\title{
Governança corporativa em empresas estatais: avanços, propostas e limitações*
}

\author{
Joaquim Rubens Fontes Filho** \\ Lidice Meireles Picolin***
}

SumÁRIo: 1. Introdução; 2 . Governança corporativa: importância para empresas e países; 3. Empresas estatais e governança corporativa; 4. Diretrizes da OCDE para a governança corporativa de empresas estatais; 5 . Considerações finais.

Summary: 1 . Introduction; 2 . The importance of corporate governance for companies and countries; 3. State-owned enterprises and corporate governance; 4. OECD guidelines for corporate governance of state-owned enterprises; 5. Final remarks.

Palavras-chave: empresa estatal; governança corporativa; problema de agência; accountability.

KEY WORDS: state-owned enterprise; corporate governance; agency problems; accountability.

Apesar do amplo processo de desestatização ocorrido internacionalmente nas décadas de 1980 e 1990, as empresas estatais permanecem desempenhando significativo papel na implementação de políticas públicas e na oferta de bens e serviços à sociedade. Entretanto, sua natureza institucional e estrutura de controle tornam complexas as

\footnotetext{
* Artigo recebido em mar. 2006 e aceito em set. 2007. Uma versão anterior deste artigo foi apresentada no X Congreso Internacional del Clad sobre la Reforma del Estado y de la Administración Pública. Santiago, Chile, out. 2005.

** Doutor em administração pela Escola Brasileira de Administração Pública e de Empresas da Fundação Getulio Vargas (Ebape/FGV). Foi gerente de planejamento estratégico da Previ e assessor da presidência no Banco do Brasil. Endereço: Praia de Botafogo, 190 - CEP 22253-900, Rio de Janeiro, RJ, Brasil. E-mail: jorubens@globo.com.

*** Coordenadora operacional de projetos e programas da Fundação Getulio Vargas. Mestre em economia empresarial pela Universidade Cândido Mendes. Curso de Política e Administração de Empresas Estatais pelo Institute Français de Gestion - Paris. Tem atuado na área de consultoria desde 1990, com trabalhos desenvolvidos em diversas organizações públicas e privadas. Endereço: Praia de Botafogo, 190/6a andar - CEP 22253-900, Rio de Janeiro, RJ, Brasil. E-mail: lidice@ fgv.br.
} 
definições de seus objetivos operacionais, a avaliação de seu desempenho, e a própria gestão executiva das empresas, já que sua atuação está sujeita tanto às necessidades de seu controlador imediato, o governo; quanto aos interesses difusos de seu controlador indireto, a sociedade, além das expectativas de retorno financeiro dos sócios privados nas sociedades de economia mista. No momento que a Organização para a Cooperação e Desenvolvimento Econômico (OCDE) propõe diretrizes para a governança corporativa de empresas estatais, que estabelecem referências para o relacionamento entre Estado, conselheiros, gestores, investidores e outras partes interessadas, este artigo avalia essas diretrizes quanto à adequação das propostas ao contexto das estatais brasileiras e sua possibilidade de implementação.

\section{Corporate governance of state-owned enterprises: advances, proposals and limitations}

Despite the extensive process of privatization that has been undertaken in many countries during the 80 s and 90s, the state-owned enterprises (SOEs) remain performing an important role in the implementation of public policies and in the offering of goods and services to the society. Meanwhile, their institutional nature and control structure make it complex to define their operational objectives, to assess their performance and even to manage them, as their work depends on the guidance of their direct controller, the State, but also on the diffuse interests of their indirect controller, the society, plus the expectations of the private investors in public listed SOEs. In this context, this article analyzes the guidelines for the corporate governance of SOEs, proposed by the Organisation for Economic Co-operation and Development (OECD) in 2005, which establishes references for the relationship between the State, board members, managers, investors and other stakeholders in the SOEs. The article discusses the adequacy of those guidelines for Brazilian SOEs and investigate their potential impact on the State's capacity to monitor and control its companies.

\section{Introdução}

As discussões em torno do papel do Estado, seu tamanho e forma de atuação, e a melhor configuração do aparelho estatal para cumprir esse papel são recorrentes na literatura de diversos campos do conhecimento, particularmente na economia, ciência política e administração pública. Naturalmente, as propostas estão associadas a determinados modelos econômicos e ideologias, mas, salvo em situações teóricas, permanece a idéia de um contínuo entre os limites de público-privado sobre o qual se situam os Estados constituídos.

Haverá sempre, em algum grau, organizações estatais destinadas a suportar a implementação das funções do Estado. Esse conjunto de organizações que integram o aparelho estatal pode ser dividido em organizações diretamente ligadas à estrutura do Poder Executivo, sem autonomia e em geral 
responsáveis por empreender funções típicas de Estado, e organizações com personalidade jurídica própria, com maior autonomia de ação, a exemplo de empresas estatais, sejam elas públicas ou sociedades de economia mista, com participação de capital privado.

Mesmo com o processo de privatização realizado nos mais diversos países ao longo das décadas de 1980 e 1990, as empresas estatais ainda hoje chegam a representar, em diferentes países associados à Organização para a Cooperação e Desenvolvimento Econômico (OCDE), até 20\% do valor adicionado, cerca de $10 \%$ do emprego e até $40 \%$ da capitalização de mercado (OECD, 2004b).

Tendo em vista a importância dessas organizações, alinhada a sua missão de oferecer referências para a atuação de governos, órgãos reguladores e agentes econômicos, a OCDE apresentou, em abril de 2005, proposta de diretrizes para promover melhores práticas de governança na atuação das empresas estatais. A partir da referência das diretrizes de governança corporativa para empresas privadas, divulgadas pela organização em 2004, foram realizadas diversas rodadas de discussão a fim de permitir que esse conjunto geral de diretrizes incorporasse também dimensões e necessidades típicas das empresas estatais e do Estado no papel de controlador (OECD, 2004a).

As diretrizes de governança corporativa das empresas estatais da OCDE consolidam um trabalho de dois anos de consultas públicas e fóruns de discussão, envolvendo tanto os 30 países-membros quanto não-membros. Este artigo analisa a adequação dessas propostas ao contexto das relações do Estado e suas organizações empresariais no Brasil, particularmente ao nível federal, e avalia o impacto dessas recomendações sobre o controle e desempenho das empresas estatais.

\section{Governança corporativa: importância para empresas e países}

As definições de governança corporativa seguem, de forma predominante, uma vertente financeira, associando-a ao desenho de um sistema que facilite o acesso e o controle de investidores sobre as empresas das quais participam. Conforme a definição de Shleifer e Vishny (1997:737), "a governança corporativa trata das maneiras pelas quais os fornecedores de recursos às corporações se asseguram que irão obter retorno de seus investimentos". Nessa perspectiva, no que se refere à iniciativa privada, a principal preocupação de governos e legisladores deve ser promover ambientes econômico e institucional adequados a esses investimentos. 
Cabe observar que a expressão "corporativa" pressupõe um modelo empresarial pelo qual a organização é uma entidade legal, separada de seus proprietários, com a propriedade representada por ações (Fitch, 1997). Entretanto, no caso das empresas estatais brasileiras, uma significativa parcela não é constituída na modalidade de ações, mas como empresa pública, de capital fechado.

Uma das primeiras e mais importantes definições de governança corporativa foi utilizada na elaboração do relatório Cadbury, no Reino Unido, que qualifica a governança corporativa como o sistema pelo qual as companhias são dirigidas e controladas (The Committee, 1992). Para a OCDE, a governança corporativa está relacionada aos mecanismos pelos quais as empresas são dirigidas e, particularmente, à maneira pela qual aqueles que controlam a gestão do dia-a-dia da empresa são responsabilizados por seu desempenho (OECD, 2004a). No Brasil, as definições propostas pelo Instituto Brasileiro de Governança Corporativa (IBGC) e pela Comissão de Valores Mobiliários (CVM) seguem orientações semelhantes, focando no governo estratégico das empresas e na otimização do seu desempenho e proteção às partes interessadas.

A origem da preocupação com a governança corporativa pode ser associada aos movimentos de crescimento e diversificação das empresas, o que exigiu a profissionalização e especialização de uma nova classe de empregados. McCraw (1998) analisa os estudos de Alfred Chandler, em que este historiador mostra como a separação entre propriedade e gestão, acelerada no caso americano na metade do século XIX, permitiu a formação de uma classe de administradores especialistas, o que contribuiu para alavancar o próprio capitalismo. Na década de 1930, em texto clássico, Berle e Means (1932) mostraram como as empresas americanas constituíam um sistema disperso de propriedade, o que originava conflitos entre administradores e acionistas decorrentes de situações de oportunismo gerencial, o que se convencionou considerar impulsionador da exigência de melhores práticas de governança.

Entretanto, o modelo que se configura hoje na maioria dos países, em especial na América Latina, não é de uma propriedade pulverizada, mas exatamente o oposto. A concentração da propriedade em investidores individuais, famílias, governos ou ainda o controle via acordo entre acionistas tem predominado, configurando cenário no qual o problema principal deixa de ser entre proprietário e gestor para se situar na relação entre acionistas majoritários e minoritários. Conforme Sanz e Holán (2004:41), "uma estimativa geral é que os cinco maiores acionistas de uma típica empresa latino-americana possuem cerca de $80 \%$ do capital social". Além disso, muitas vezes, acionistas, direção e conselho de administração pertencem à mesma família, sendo usual também 
que o sócio majoritário controle uma parte importante da gerência da empresa. No Brasil, os estudos de Carvalhal (2002) e Leal e Silva (2008) evidenciam também a elevada concentração da propriedade presente nas empresas listadas na Bovespa.

Para Oman e Blume (2005), um sistema nacional de governança corporativa compreende tanto as regras formais e informais quanto práticas aceitas e mecanismos de reforço, público e privado, que regem as relações entre gestores e investidores. Carvalho (2002) discute por que as questões de governança corporativa, a princípio assumidas como relacionamento exclusivo entre partes privadas, se tornam um problema de interesse público. Boas práticas de governança, que reduzem a assimetria de informações entre investidores e gestores ou empreendedores, e o equilíbrio de direitos entre acionistas majoritários e minoritários fortalecem o mercado de capitais como mecanismo de financiamento às empresas. Esse fortalecimento amplia o nível de liquidez do mercado, o que reduz o prêmio de risco e torna menos onerosa a captação de recursos pela empresa. A isso deve se acrescer a proteção legal aos credores, tanto de crédito quanto de equity. Esse sistema de equilíbrio nas relações e segurança legal, ao facilitar o fluxo de recursos às empresas, tem papel importante para a promoção do desenvolvimento econômico e financeiro dos países.

Conforme aumenta o valor das empresas no mercado, boas práticas de governança corporativa ampliam também os atrativos aos investimentos em ações, trazendo recursos ao mercado de capitais e dando liquidez ao mercado secundário. Para o governo, o crescimento desses mercados traz, como conseqüência, um maior fluxo de investimentos externos para o país e uma ampliação das fontes de capital para o desenvolvimento empresarial e a indução a projetos privados. Para a sociedade, a construção de um ambiente empresarial mais robusto se reflete diretamente no aumento da arrecadação de impostos e na expansão dos níveis de emprego. Da perspectiva dos empregados, práticas de transparência, orientação para criação de valor e prestação de contas tendem a promover um ambiente mais propenso à participação, meritocracia e desenvolvimento profissional, associados a gratificações por desempenho, além de dificultar a adoção de práticas clientelistas nas relações de e com superiores hierárquicos.

Cabe destacar, contudo, que o uso e reforço dessas práticas retiram poder discricionário dos gestores, retornando esse poder aos investidores na empresa, que representam o conjunto de indivíduos com direitos residuais. A cadeia de comando passa a se orientar da propriedade para a execução, conduzida pelo corpo de executivos e mediada pelo conselho de administração 
(board of directors). Ainda que com isso os gestores tenham sua liberdade de ação diminuída, passam a compartilhar responsabilidades e a contar com o apoio, experiência e conhecimento dos membros do conselho, facilitando também as articulações com o conjunto dos acionistas.

Uma proxy utilizada para examinar a situação das práticas de governança corporativa nos países é o prêmio de controle, representado pela diferença entre o preço pago por ações do bloco de controle e as demais, e que indiretamente exprime a extensão, percebida; em controladores expropriam valor da empresa relativamente aos minoritários. Conforme Oman e Blume (2005), durante a década de 1990, a diferença média nas economias em transição dos países da Europa Central foi de 35\%, com 58\% na República Tcheca, 11\% na Polônia, enquanto na América Latina foi de 33\%, atingindo 65\% no Brasil. Esses valores são extremamente elevados quando comparados aos $2 \%$ dos Estados Unidos, Reino Unido e África do Sul, e os 8\% da Europa não-anglosaxônica (1\% na Noruega, 2\% na França e 37\% na Itália).

Oman e Blume (2005) classificam três técnicas que podem ser utilizadas para expropriar valor de acionistas fora do bloco de controle: estruturas piramidais, pela qual um acionista controla $51 \%$ de uma companhia que, por sua vez, controla outros $51 \%$ das ações votantes de uma segunda companhia. Outras técnicas seriam o cruzamento de controle, quando uma firma possui ações de outra e vice-versa, e a oferta de múltiplas classes de ações com direitos diferenciados sobre o controle e fluxo de dividendos.

Observando os sistemas legais e instituições de reforço às boas práticas de governança corporativa, La Porta, Lopez-de-Silanes e Shleifer (1998) analisaram, na década de 1990, 49 países distribuídos nos vários continentes, entre os quais nove da América Latina: Argentina, Brasil, Chile, Colômbia, Equador, México, Peru, Uruguai e Venezuela. Foram considerados diversos aspectos associados à governança tais como proteção a acionistas minoritários, proteção a credores, padrões contábeis, eficiência do sistema judiciário e nível de corrupção. Os resultados encontrados mostraram a deficiência do ambiente institucional desses países, no que se refere ao conjunto das práticas de governança corporativa, frente aos demais integrantes da amostra.

A capacidade de captação de recursos via bolsas de valores permite também identificar as deficiências dos países latino-americanos em relação, principalmente, aos do bloco anglo-saxão. Embora a capitalização média das empresas brasileiras - expressa pela relação entre o valor total de mercado das companhias listadas em bolsa e o número dessas companhias - tenha crescido $1.490 \%$ entre 1990 e 2002, saltando de US\$ 19 milhões para US\$ 308, a capitalização relativa - dada pela capitalização média dividida 
pelo produto interno bruto - ficou em $28,25 \%$ em 2002, valor próximo ao de outros países latino-americanos como Argentina e México, com respectivamente $16,09 \%$ e $16,20 \%$, mas muito abaixo de países anglo-saxões como Estados Unidos, com 105,83\% e Reino Unido, com 114,64\%.

A situação evidenciada pela estrutura de propriedade, pelo prêmio de controle, capitalização bursátil e, mais profundamente, pelos estudos de La Porta, Lopez-de-Silanes e Shleifer (1998) configuram um ambiente institucional que apresenta sérias deficiências relativamente a padrões internacionais de governança corporativa. Como conseqüência, as empresas latino-americanas têm maiores dificuldades para atrair investidores interessados em participar de seu capital, elevando os prêmios de risco e o custo do dinheiro, com reflexos em perda de competitividade. Nesse contexto, além de fortalecer o ambiente institucional, os governos desses países podem assumir um papel de liderança significativo, promovendo em suas empresas estatais a melhoria das práticas de governança, o que certamente induzirá empresas do setor privado a seguir esse exemplo.

É importante registrar os significativos avanços ocorridos no ambiente brasileiro ao longo desta década. A criação do Novo Mercado da Bovespa, as mudanças introduzidas na legislação societária, a atuação da Comissão de Valores Mobiliários na regulação do mercado somaram-se às condições favoráveis trazidas por um ambiente de estabilidade econômica, crescente liquidez internacional e valorização das commodities para impulsionar a capitalização bursátil e o volume de transações nas bolsas.

Entre janeiro de 2001 e de 2008, segundo informações do informe técnico da Bolsa de Valores de São Paulo, o valor de mercado das empresas listadas cresceu mais de 500\%, saltando de US\$ 251 bilhões para US\$ 1.293 bilhões, enquanto os volumes totais negociados no mercado à vista variaram de US\$ 54,2 bilhões para US\$ 531,6 bilhões entre os anos de 2001 e 2007.

\section{Empresas estatais e governança corporativa}

Conforme Esfahani e Ardakani (2002), os motivos que justificam a propriedade estatal podem ser associados tanto a questões de ideologia quanto a deficiências das instituições estatais em assegurar determinados direitos e garantias à população. $\mathrm{O}$ primeiro motivo se refere a uma orientação ideológica de governo, seguindo uma visão mais nacionalista ou uma retórica socialista. As demais teorias sobre a propriedade estatal focam-se no papel dessas empresas na redistribuição da renda, embora, conforme argumentam esses autores, 
essa justificativa não seja capaz de explicar plenamente esse papel, dado que políticas tributárias e subsídios poderiam ser utilizados alternativamente de forma mais eficiente.

A propriedade estatal poderia então ser justificada pela ausência de mecanismos institucionais que garantissem à iniciativa privada que as políticas redistributivas não retirariam as quasi renda de seus investimentos. Ou seja, "o motivo para a propriedade estatal é assegurar investimentos em ativos socialmente valiosos que não podem ser realizados por investidores privados devido aos riscos de expropriação" (Esfahani e Ardakani, 2002:5). A incapacidade do Estado em garantir um ambiente regulatório e fiscal que promova o investimento privado poderia, portanto, explicar a necessidade de sua atuação na produção.

Em ambientes com falhas de mercado pode ser apontada outra razão para a propriedade estatal, denominada por Perotti (2004) como problema do comprometimento privado. A dificuldade encontrada pelo Estado em controlar indiretamente o comportamento dos agentes privados, em virtude principalmente de deficiências do ambiente institucional, ou ainda em situações que caracterizem um monopólio natural, pode funcionar como justificativa para sua ação direta no controle das empresas. Essa razão pode ser exemplificada pela propriedade, pela União ou por unidades da federação, de empresas de água e esgoto.

A configuração da empresa estatal apresenta variação entre os países, desde modelos fechados, sem participação de investidores privados, a modelos onde a participação é intensa, embora o proprietário permaneça como instância de governo.

No Brasil, o Decreto-Lei no 200, de fevereiro de 1967, dispôs sobre a estrutura e funcionamento da administração federal, caracterizando nesse âmbito a estrutura da administração direta e indireta no país. O seu art. $4^{\circ}$ estabelece que a administração indireta compreenda autarquias, empresas públicas e sociedades de economia mista, dotadas essas organizações de personalidade jurídica própria, vinculando essas entidades ao ministério em cuja área de competência estiver enquadrada sua principal atividade (Brasil, 1967).

Para alguns autores, não deve haver diferença nos princípios que tratam da governança corporativa em empresas privadas e estatais. Conforme Barrett (citado por Ryan e NG, 2000:12):

os princípios de governança corporativa são os mesmos tanto no setor público quanto privado. Boa governança corporativa requer clara definição de responsabilidade e clara compreensão dos relacionamentos entre as partes interes- 
sadas da organização e aqueles responsáveis por administrar seus recursos e produzir seus resultados.

Entretanto, as especificidades da empresa estatal apontam para um conjunto de restrições quanto à plena adesão às práticas de governança indicadas ao setor privado (OECD, 2004b:6):

v as empresas estatais estão sujeitas a restrições mais brandas em termos orçamentários, que podem protegê-las contra ações de tomada de controle via mercado e falência. Ainda que possível, esta última situação na prática raramente ocorre, gerando pressões adicionais sobre os gastos públicos para equacionar a empresa estatal em situação financeira difícil;

$\checkmark$ muitas estatais, por sua própria natureza, operam em áreas nas quais a competição com o setor privado é pequena ou inexistente;

v os padrões de transparência e prestação de contas são diferentes daqueles do setor privado, uma vez que orientados principalmente para o controle dos gastos públicos;

จ com freqüência, não há um claro proprietário, mas vários potenciais proprietários buscando objetivos diferentes. Ministérios - um ou vários — e o Parlamento podem se alternar na condição de principal (proprietário) frente à empresa, em uma complexa relação de agência, com múltiplos e por vezes dispersos grupos de principais construindo uma cadeia difusa de accountability.

Além dessas, diversas outras características da empresa estatal devem ser consideradas na construção dos modelos de governança, tais como seu grau de autonomia e de seus objetivos e estratégias em relação ao governo; a eficiência no equacionamento dos custos de agência e de transação; e a disponibilidade de sistemas de controle e monitoramento no contexto institucional.

\section{Diretrizes da OCDE para a governança corporativa de empresas estatais}

O documento proposto pela OCDE (2005), embora direcionado ao ambiente institucional e às questões mais específicas da governança corporativa de empresas estatais dos países-membros, também recebeu sugestões de não-membros convidados. 
Está estruturado em seis áreas, que tratam respectivamente de assegurar um arcabouço regulatório e legal efetivo para empresas estatais; o Estado atuando como proprietário; eqüidade no tratamento com acionistas; relações com stakeholder; transparência e disclosure; e responsabilidades dos conselhos. Cada uma dessas áreas apresenta uma diretriz geral, seguida por itens de recomendação mais específica.

Destacamos as principais diretrizes e recomendações da OCDE (2005), segundo a área em que são apresentadas e sua importância para a construção de um quadro referencial para a governança corporativa das empresas estatais brasileiras, particularmente no plano federal, seguidas pelas respectivas análises.

\section{Assegurar um arcabouço legal e de regulação efetivo para as empresas estatais}

O referencial legal e regulatório das estatais deve ser desenvolvido com vistas a assegurar um ambiente de atuação para essas empresas e o setor privado em áreas onde competem e de forma a promover boas práticas de governança corporativa, seguindo nesse sentido os princípios de governança corporativa da OCDE (2004b):

จ deve haver clara separação entre a função propriedade exercida pelo Estado e as demais funções;

os governos devem simplificar a forma legal da estatal de modo a assegurar o exercício dos direitos pelos credores, inclusive quanto a pedidos de insolvência;

จ as obrigações e responsabilidades da estatal devem ser claramente discriminadas nas leis e normas;

V as estatais devem se submeter à aplicação das leis gerais e normativas;

esse arcabouço legal deve ser flexível de forma a permitir ajustes na estrutura de capital;

v as estatais devem se relacionar em bases estritamente comerciais com fornecedores de recursos financeiros.

A visão geral é delimitar claramente o espaço de atuação da empresa estatal frente às empresas privadas, evitando privilégios decorrentes de suas funções públicas, mas assegurando sua capacidade de atuação para atingir seus objetivos legalmente definidos. Assim, cabe promover o status legal da empresa estatal, igualando-a a uma empresa privada para efeitos de atuação 
no mercado, resguardando seus objetivos de governo; portanto, deve estar sujeita ao mesmo ambiente que as demais empresas, inclusive quanto às relações com fornecedores e investidores.

Seu escopo de atuação deve estar claramente limitado de forma a evitar a diversificação ou a ampliação de suas atividades a novos setores. Delimitar a atuação do agente é um princípio basilar das boas práticas de governança, dada a natureza diversa da propensão a risco e horizonte de planejamento. É natural que o agente busque ampliar sua área de atuação, seja para aumentar sua influência ou para reduzir seu risco no negócio (Amihud e Lev, 1981). No âmbito estatal, a diretriz da OCDE busca evitar que a empresa utilize de prerrogativas associadas a sua propriedade pública para reduzir o espaço da iniciativa privada.

Uma preocupação nesse documento é que, embora possam estar protegidas da falência, sob a justificativa de assegurar a continuidade da prestação de um serviço público, um elevado nível de endividamento é nocivo aos credores, ao governo e aos próprios contribuintes, além de introduzir uma distorção nos mercados. Por essa razão, deve haver uma clara distinção entre as responsabilidades do Estado e de suas empresas em relação aos credores, não cabendo uma garantia automática do Estado sobre empréstimos e demais passivos das estatais. Esse problema pode ser agravado, inclusive, em situações que bancos estatais se tornam grandes financiadores dessas empresas, suscitando conflitos de interesse ou uma eventual sensação de desobrigação no pagamento dos empréstimos realizados junto a esses bancos.

\section{O Estado atuando como proprietário}

O Estado deve agir como proprietário informado e ativo, e estabelecer uma clara e consistente política de propriedade, assegurando que a governança das empresas estatais seja conduzida de forma transparente e responsável (accountable), com o necessário grau de profissionalismo e efetividade:

- o governo deve desenvolver e divulgar uma política de propriedade que defina os objetivos globais da propriedade estatal, o papel do governo na governança corporativa das estatais, e como irá implementar sua política de propriedade;

v não deve se envolver nas atividades diárias e operacionais das empresas;

v o Estado deve permitir que os conselhos das estatais exerçam suas responsabilidades e respeitar sua independência; 
- o exercício dos direitos de propriedade deve ser claramente identificado na administração estatal, preferencialmente centralizando essa responsabilidade em um órgão único;

- deve exercitar seus direitos de propriedade de acordo com a estrutura legal de cada empresa - fazendo-se representar nas assembléias e votações; estabelecendo processo estruturado e transparente de escolha de conselheiros; estabelecendo sistemas de acompanhamento e avaliação das empresas; quando permitido, mantendo diálogo com auditores externos e órgãos estatais de controle; assegurando esquemas de remuneração aos conselheiros que permitam atrair e manter motivado pessoal qualificado.

Essa é certamente a área com as propostas mais inovadoras da OCDE, principalmente quanto à recomendação de um órgão centralizador do exercício de propriedade estatal nas empresas e o processo de escolha de conselheiros.

Seguindo a regra geral de ampliar a autonomia da empresa dentro de um conjunto predefinido de objetivos - à semelhança de um contrato de gestão - como forma de permitir controlar seu desempenho, inserem-se as principais diretrizes da área. Entretanto, certamente será tarefa árdua, mas necessária, assegurar essa independência de atuação. No caso brasileiro, avanços têm ocorrido nesse sentido, principalmente em sociedades de economia mista e, particularmente, naquelas que lançam títulos no exterior na modalidade American Depositary Receipt (ADR).

Como propõe o documento, o Estado deve clarificar e priorizar os principais objetivos da estatal, que podem incluir lucratividade e evitar distorções dos mercados. Entretanto, esses objetivos apresentam difíceis balanceamentos, tais como criar valor, melhorar um serviço público, ou assegurar estabilidade nas relações de trabalho, de forma que as proposições e políticas devem ir além de estabelecer objetivos gerais, mas também dar indicações sobre como serão alcançados os objetivos e clarificar como serão solucionados ou balanceados os esquemas de compensações entre eles (trade-offs).

No conjunto das recomendações da OCDE estão incluídas a exigência quanto à clareza da política de propriedade e sua forma de implementação, o não envolvimento do governo com as atividades operacionais das empresas, e a autonomia dos conselhos, além do pleno exercício da função propriedade, respeitado inclusive seu dever fiduciário perante a própria sociedade.

Escolha de conselheiros é um tema complexo mesmo em empresas privadas. Como discutido anteriormente, a propriedade nas empresas da América 
Latina apresenta níveis de concentração elevados, o que influencia diretamente no papel e autonomia dos conselhos de administração. Ao contrário de países que apresentam propriedade dispersa, a concentração reduz os problemas do denominado efeito carona (free rider) e de ações oportunistas dos gestores, mas gera desequilíbrios entre acionistas majoritários e minoritários. Nesse ambiente, portanto, há grandes semelhanças entre os problemas de governança corporativa de empresas privadas e estatais brasileiras no que se refere à distribuição de poder, dada a concentração da propriedade, e na atuação dos conselhos de administração.

A concentração induz a um controle mais próximo do proprietário sobre a empresa, substituindo mesmo as funções dos conselhos ou reduzindo sua importância. As idéias contemporâneas de independência do conselho, presentes na maioria dos códigos de boas práticas de governança corporativa, visam evitar que acionistas majoritários expropriem minoritários, uma vez que membros independentes conferem maior autonomia ao órgão e uma orientação para o bem da empresa e a geração de valor, desvinculando sua atuação dos anseios específicos de sócios controladores. Assim, a independência total ou parcial do conselho, caracterizada pela não vinculação funcional de seus membros à empresa ou ente controlador, mostra-se não apenas indicada mas necessária.

Na prática, contudo, não representa uma mudança simples. Assim como o majoritário em uma empresa privada procura assegurar sua influência, seja diretamente ou via conselho, problema semelhante pode ocorrer na empresa estatal, amplificado por sua natureza política. É notória a indicação dos gestores diretamente pela liderança do Poder Executivo (ver Ribeiro e Borges, 2007), suprimindo dessa forma um papel fundamental dos conselhos e retirando-lhe um instrumento para o exercício de seu papel de supervisão do desempenho da empresa.

A recomendação da OCDE também é pelo estabelecimento de um processo estruturado e transparente de escolha de conselheiros e por assegurar esquemas de remuneração que permitam atrair e manter a motivação desses profissionais. Dois desafios que novamente configuram uma situação desejável, dentro da ótica geral dos princípios, de atribuir autonomia à empresa estatal e cobrar resultados.

Decerto o ponto mais inovador desta área, se não de todo o documento, se refere à diretriz para que se promova uma clara separação entre a função propriedade e outros papéis do Estado, unificando a responsabilidade por exercer tal função. Entre outros pontos, argumenta a OCDE que uma confusão nesses casos pode fazer com que a empresa estatal seja percebida apenas 
como instrumento da política industrial e não como um ativo cujo valor deve ser protegido e aumentado por seu proprietário, o Estado. Além disso, como o Estado tem poder para regular e atuar no mercado, é fundamental uma clara separação entre essas funções.

É certo que essa centralização deve evitar ser uma nova e poderosa camada de burocracia. Centralização da função propriedade não implica centralização da propriedade legal. Ao órgão centralizador cabe harmonizar e coordenar ações e políticas empreendidas por diferentes áreas ou órgãos representantes da propriedade em vários ministérios e ser responsável por elaborar uma política global, desenvolvendo diretrizes específicas e unificando práticas de governança. A centralização da função propriedade em uma entidade única é mais relevante para empresas estatais atuando em setores competitivos.

No Brasil, a supervisão e controle das empresas estatais estão distribuídos segundo os aspectos de gestão corporativa e política de negócios; planejamento dos investimentos e acompanhamento das estatais; gestão das participações acionárias (administração de portfólio).

A primeira dessas funções permanece no âmbito do ministério supervisor, segundo a área de competência em que estiver enquadrada sua principal atividade. Cabe a esse ministério alinhar e acompanhar a execução dos objetivos da empresa às políticas governamentais no setor.

A função de planejamento e acompanhamento, abrangendo o conjunto das estatais, é desempenhada no âmbito do Ministério do Planejamento, pelo Departamento de Coordenação e Controle das Empresas Estatais (Dest). A esse órgão cabem as funções de coordenar a elaboração do Programa de Dispêndios Globais e da proposta do Orçamento de Investimento das empresas estatais, bem como promover a articulação e a integração das políticas das empresas estatais, inclusive política salarial e de benefícios.

A gestão do portfólio é responsabilidade do Ministério da Fazenda, por meio da Secretaria do Tesouro Nacional, órgão responsável pela administração dos haveres da União junto a terceiros, inclusive as participações acionárias. À sua condução vinculam-se as ações voltadas para a gestão do ativo, do portfólio e condução de atos de natureza societária, como participação em assembléias de acionistas.

As diretrizes da OCDE recomendam a centralização da função propriedade em uma única área, sob o argumento de que uma divisão difusa de responsabilidades entre múltiplas autoridades pode conduzir à falta de coerência ou consistência no referencial institucional. Levantamento realizado pela OCDE junto aos países-membros quanto à organização da função propriedade mostrou que, internacionalmente, três modelos se destacavam (OCDE, 2004b). 
No primeiro modelo, denominado descentralizado ou "ministro-setorial", as empresas estatais encontram-se sob a responsabilidade de ministérios específicos, incumbidos de desempenhar as políticas de governo associadas à natureza da empresa. Esse modelo predominou nos países do antigo bloco socialista, como República Tcheca, Polônia e Hungria, funcionando ainda hoje na República Eslovaca, Finlândia e, com algumas variações, também na Alemanha, onde o Ministério das Finanças exerce o papel de estabelecer diretrizes gerais para a propriedade e políticas de privatização (2004b:24). As vantagens desse modelo estão em concentrar a expertise do setor e ampliar a capacidade estatal para implementar políticas industriais específicas, vantagens que se reduzem com uma mudança de orientação na organização sistêmica e nos objetivos das estatais para uma abordagem mais estrutural, baseada na atuação conjunta das empresas (framework-oriented) e na agregação global à economia, e não apenas como instrumentos pontuais de política industrial.

Um segundo modelo identificado pela OCDE (2004b) é denominado modelo dual (dual ministry model), por meio do qual dois ministérios dividem a responsabilidade pela propriedade da empresa estatal. Usualmente, há um ministério setorial específico e um comum a todas as empresas, em geral o Ministério de Finanças ou equivalente, que dividem responsabilidades sobre certos aspectos da empresa, tais como nomear os membros do conselho.

O exemplo da Nova Zelândia permite evidenciar as diferenças desse modelo frente ao anterior. Nesse país, o Ministério de Finanças trata as questões de eficiência econômica e impactos fiscais da atuação das estatais. O ministério setorial segue uma orientação comercial, acompanhando seu desempenho e enfatizando a busca pelo bom desempenho econômico da empresa.

O estudo da OCDE (2004a) comenta os casos da Turquia e Coréia, nos quais ocorre um modelo triplo, com pelo menos três ministérios envolvidos. Na Coréia, o Ministério das Finanças e Economia representa o governo nas assembléias gerais das empresas, o ministério setorial propõe os conselheiros e executivos, e o Ministério de Orçamento e Planejamento indica conselheiros independentes e auditores, e acompanha o desempenho da empresa. $\mathrm{Na}$ Turquia, o Tesouro é o proprietário legal da empresa estatal, e tem como atribuições apontar os representantes nos conselhos e participar das assembléias gerais; o órgão de planejamento estatal e o Tesouro supervisionam o desempenho da empresa e ao ministério setorial cabe ainda apontar outro membro do conselho (OECD, 2004b:27).

Esse modelo dual, ou triplo, apresenta grande semelhança com o caso brasileiro, onde três ministérios, o supervisor, o Ministério da Fazenda e o Ministério do Planejamento exercem essas funções de forma complementar. 
O terceiro modelo, denominado centralizado, é caracterizado por uma forte concentração da função propriedade, subordinada na maioria dos casos ao Ministério das Finanças, como na Dinamarca, Holanda e Espanha, ou ainda ao Ministério da Indústria ou a uma agência específica, a exemplo da Noruega e Suécia. A adoção desse modelo é recente na maioria dos países e representa a possibilidade de clarificar responsabilidades entre diferentes órgãos e funções governamentais e exercer com mais consistência a função-propriedade. É o modelo apontado pela OCDE (2004b) como o mais efetivo, e que certamente serviu de base para as propostas de centralização da função propriedade no documento das diretrizes.

Alinhado às recomendações da OCDE, o Executivo brasileiro promulgou, em janeiro de 2007, o Decreto ํㅡ 6.021, instituindo a Comissão Interministerial de Governança Corporativa e de Administração de Participações Societárias da União (CGPAR), composta pelos ministros do Planejamento, da Fazenda e da Casa Civil. Entre suas competências, cabe à CGPAR aprovar diretrizes e estratégias relacionadas à participação acionária da União nas empresas estatais federais, estabelecer critérios para avaliação dessas empresas e para indicação de diretores e representantes da União nos conselhos de administração e fiscal, estabelecendo diretrizes e padrões de conduta ética para sua atuação. A CGPAR, quando em funcionamento, deverá contribuir com significativos avanços na organização e orientação do sistema de empresas estatais federais.

\section{Tratamento eqüitativo dos acionistas}

O Estado e empresas estatais devem reconhecer o direito de todos os acionistas e assegurar a eqüidade no tratamento e igual acesso à informação da empresa, como referido nos princípios de governança corporativa da OCDE.

O Estado deve ser exemplar nesse comportamento e seguir as melhores práticas relacionadas ao igual tratamento de acionistas minoritários:

v a entidade de coordenação ou função propriedade e a estatal devem assegurar a eqüidade no tratamento aos acionistas;

v as empresas devem observar um alto grau de transparência com todos os acionistas;

v as estatais devem desenvolver uma ativa política de comunicação e consulta com todos os acionistas; 
v a participação de acionistas minoritários em assembléias deve ser facilitada para permitir que tomem parte de decisões importantes, a exemplo da escolha dos membros do conselho.

A diretriz, e recomendações vinculadas, delineadas nessa área são aplicáveis às estatais constituídas na forma de sociedade anônima, particularmente aquelas de capital aberto e com ações negociadas em bolsas de valores. No caso das estatais federais brasileiras, de um total de 135 empresas, incluindo subsidiárias (Dest, 2006), apenas oito - Banco do Brasil, Petrobras, Eletrobrás, Basa, BNB, BEC, Besc e BEP - se enquadram nessa situação de capital aberto e apenas as três primeiras apresentam volume significativo de transações de suas ações. Contudo, mesmo em pequeno número, a importância econômica dessas empresas é significativa, segundo Oliveira (2005):

Os técnicos do Ministério do Planejamento confirmam. As maiores estatais são de capital aberto, com ações negociadas em bolsa. O investimento anual delas é estimado em cerca de R $\$ 36$ bilhões (em torno de US\$ 14 bilhões). Seus ativos somaram R $\$ 860$ bilhões em 2004, ou US\$ 350 bilhões, acrescentam os técnicos.

Uma questão fundamental no caso brasileiro se refere à legislação societária vigente, que permite duas classes de ações, com e sem direito a voto. Como regra geral, as melhores práticas de governança corporativa, a exemplo da divulgada pelo Instituto Brasileiro de Governança Corporativa (IBGC) (2005:11) e da própria OCDE (2004a:20), recomendam a prática de "uma ação, um voto". A adoção desse mecanismo, que daria maior equilíbrio de poder aos acionistas, encontra-se inclusive como requisito no denominado Novo Mercado da Bovespa, onde são negociadas ações de empresas com práticas recomendadas de governança.

Essa não seria uma mudança elementar para as estatais no Brasil, dado que a simples transformação das ações sem direito a voto em ações votantes retiraria do Estado a maioria no controle da empresa ou exigiria um elevado aporte de recursos para manter a empresa na condição de estatal. Dada a regulamentação em vigor até a promulgação da Lei ํo 10.303 , em outubro de 2001, o capital social podia ser formado por até $2 / 3$ de ações sem direito a voto. Bastaria portanto ao Estado controlar metade das ações votantes (1/6 ou 17\%) para ter o controle integral da empresa. Assim, para igualar o direito de voto das ações e não perder o controle das empresas - mantendo-as na condição de estatal - deveriam ser adquiridas pelo Estado no mínimo mais 
2/3 mais um de ações, em um eventual processo de conversão, considerando que a participação estatal já é razoavelmente maior que esse limite mínimo de controle.

Entre as recomendações feitas nessa área está a de assegurar a participação dos minoritários no processo decisório, permitindo, por exemplo, o uso de voto cumulativo, para que os minoritários possam concentrar seus direitos de voto em um mesmo diretor e balancear, com isso, o poder dos majoritários. Observe-se que essas recomendações já estão contidas na Lei das Sociedades Anônimas (Lei ㄲo 6.404/76), contempladas as incorporações da Lei ㄲo 10.303, de 2001, legislação seguida também pelas estatais listadas em bolsa.

\section{Relações com stakeholders}

A política de propriedade estatal deve reconhecer plenamente as responsabilidades dessas empresas com grupos de interesse (stakeholders) e demanda a divulgação dos termos e práticas de relacionamento com esses grupos. São recomendações vinculadas a essa diretriz:

v o governo, a entidade coordenadora e as próprias estatais devem reconhecer e proteger direitos dos stakeholders estabelecidos por lei ou por acordo mútuo, e se referir aos princípios a esse respeito;

v grandes empresas estatais ou aquelas de capital aberto listadas em bolsas de valores devem comunicar em relatórios suas relações com stakeholers, assim como aquelas que desempenham papéis ou objetivos importantes de políticas públicas;

- o conselho da empresa estatal deve desenvolver e aplicar programas de compliance relacionados a códigos de ética internos.

O relacionamento estável com grupos de interesse representa um importante capital social ou ativo intangível para as empresas, que pode ser entendido inclusive como estratégia de longo prazo. No caso de estatais, como patrimônio público, a preocupação com esse relacionamento deve ser prioridade, pelo efeito demonstração que apresentam. Principalmente em países em desenvolvimento, onde o ambiente institucional e as práticas empresarias encontram-se em consolidação, cabe às empresas estatais a responsabilidade adicional de promover o comportamento ético e o bom nível nos relacionamentos entre empresas e sociedade, criando exemplos e liderando iniciativas que estimulem melhores práticas de governança. 
O documento reconhece, nessa área, a ampliação do papel das empresas e a necessidade de seu compromisso com a sociedade, com o interesse coletivo.

\section{Transparência e abertura das informações (disclosure)}

Empresas estatais devem observar elevados padrões de transparência, em concordância com os princípios de governança corporativa da OCDE (2004a):

- a entidade de coordenação ou função propriedade deve desenvolver e divulgar relatórios consistentes e agregados sobre as empresas, e publicar anualmente um relatório agregado sobre as empresas estatais;

v estatais devem desenvolver eficientes procedimentos e funções de auditoria interna, sob o controle do conselho e se reportando a ele ou ao comitê de auditoria;

- empresas estatais, especialmente as maiores, devem estar sujeitas a auditoria externa independente anual, baseada em padrões internacionais. A existência de procedimentos específicos de controle estatal não substitui a auditoria externa;

- empresas estatais devem estar sujeitas aos mesmos padrões de qualidade e auditoria que companhias listadas em bolsa (abertas). Estatais grandes ou listadas devem abrir suas informações financeiras e não financeiras segundo melhores práticas internacionais, assim como aquelas desempenhando papéis ou objetivos importantes de política pública;

v as estatais devem abrir informação material sobre todos os assuntos descritos nos princípios de governança corporativa da OCDE e adicionalmente focar em áreas de significante atenção para o Estado como um proprietário e o público em geral. São exemplos dessas informações: uma clara declaração dos objetivos da companhia deve ser fornecida ao público em geral, bem como relatórios reportando quanto ao cumprimento desses objetivos; a estrutura de propriedade e votação das estatais deve ser transparente; atenção específica deve ser dada à adequada abertura de fatores de risco material; a comunicação deve detalhar qualquer assistência financeira, inclusive garantias, recebida do Estado e comprometimentos que realize em benefício das estatais; transações materiais realizadas com entidades relacionadas. 
As novidades desta área para as empresas estatais estão, principalmente, na recomendação de relatório agregado sobre o conjunto das empresas. Embora possa se argumentar quanto à dificuldade da produção de tal documento, a possibilidade de uma visão consolidada sobre a função propriedade estatal e suas práticas de gestão e desempenho acarretará avanços significativos para a transparência de todo o sistema estatal.

$\mathrm{O}$ documento recomenda maior transparência da função propriedade e independência para a atuação da empresa, principalmente quanto aos processos de votação. O item $e$, em seu inciso 4 , destaca também a necessidade de divulgar - e separar - o risco e custos da atuação estatal, enquanto o inciso 5 recomenda também a transparência no relacionamento com entidades relacionadas. Essas medidas vão ao encontro da necessidade de se permitir uma melhor avaliação do resultado da empresa per si, evitando que ela se responsabilize por passivos de outras áreas do setor público.

Uma vez que a sociedade é, em última instância, a proprietária das empresas estatais - o que representa uma complexa relação de agência — cabe às estatais serem, no mínimo, tão transparentes quanto as corporações privadas. Dada sua importância para promover as boas práticas de governança corporativa no país, é correto recomendar que princípios de transparência sejam seguidos de forma exemplar.

O documento da OCDE destaca que, quando uma estatal também é utilizada para propósitos políticos, deve ser reportado como tais propósitos foram alcançados e a que custo. Lembra também que, sem adequada informação sobre fatores de risco, essas empresas podem dar uma falsa representação de sua situação financeira e desempenho global. Recomenda que a abertura do risco deva ser considerada prioridade em setores recentemente liberalizados ou crescentemente internacionalizados. Essa abertura requer o estabelecimento de sólido sistema interno de gestão de risco para identificar, gerenciar, controlar e reportar esses riscos, reportando também os denominados itens off-balance sheet, referentes a aspectos não incluídos no balanço e que afetam o valor e resultados da empresa como alianças, garantias e arrendamento de equipamentos, bem como estratégias para sua gestão.

\section{Responsabilidades do conselho de administração da empresa estatal}

Os conselhos das empresas estatais devem possuir adequada autoridade, competência e objetividade para desempenhar suas funções de condutores da es- 
tratégia e monitoramento dos gestores. O conselho deve agir com integridade e ser responsável por suas ações:

- os membros dos conselhos das estatais devem ter mandato e responsabilidades claramente definidos, inclusive quanto ao desempenho da estatal;

v devem exercer julgamento objetivo e independente. O conselho deve ser formado por membros com relevante competência e experiência, e incluir um número suficiente de não-executivos e membros independentes. O número de seus membros deve ser limitado e sua nomeação ocorrer por processo transparente;

- nas empresas onde a representação dos empregados no conselho é autorizada, devem ser desenvolvidos mecanismos para garantir que sua voz seja exercida efetivamente;

- o presidente do conselho deve ter relevantes competências para desempenhar seu papel, e as boas práticas de governança apontam que deve ser separada a figura do presidente do conselho e a do presidente executivo;

v os conselhos das empresas estatais devem desempenhar suas funções de monitoramento da gestão e direcionamento estratégico, sujeitos aos objetivos ditados pelo governo e pela entidade coordenadora. Devem ter poder para indicar e destituir o presidente executivo;

v quando necessário, o conselho pode constituir comitês especializados para apoiá-lo em suas funções essenciais, particularmente comitês de auditoria, risco, de remuneração, nomeação e ética;

v os conselhos das estatais devem fazer avaliação anual de seu desempenho.

Nessa área, as diretrizes da OCDE guardam grandes semelhanças com as diretrizes gerais, aplicáveis ao setor privado. O papel do conselho como condutor das estratégias gerais da empresa, sua independência, capacitação e formação são princípios gerais.

São também princípios gerais suas obrigações quanto ao monitoramento dos executivos, os requisitos de competência, a exigência de serem submetidos a uma avaliação anual, a constituição de comitês para assuntos específicos, e a separação entre a figura do presidente do conselho e do presidente executivo.

Um ponto importante que observa o documento é que as funções do conselho podem, eventualmente, ser duplicadas por órgãos reguladores em algumas áreas, por isso a exigência de clareza nas funções do conselho e na 
função direta do Estado na propriedade. O documento contempla ainda a recomendação de que os conselhos sejam formados por número suficiente de membros externos e independentes, principalmente em ambientes mais competitivos de atuação, que sejam livres de conflitos de interesse, e preferencialmente recrutados no setor privado, medidas que ajudarão a tornar o conselho mais orientado a negócios. Além disso, indica que o número dos membros do conselho que vêm diretamente da administração estatal deve ser reduzido, para limitar interferência política direta e indevida, e sugere explicitamente excluir do conselho ministro, secretários de Estado e membros do Parlamento, e evitar aqueles com representação política. Objetivos políticos amplos devem ser canalizados por meio da entidade de coordenação.

Especificamente quanto ao contexto das empresas estatais, o texto remete novamente à indicação e independência do conselho. Um princípio que norteia todo o documento da OCDE é a independência da empresa estatal. Sua orientação para questões públicas é dada no próprio momento de criação. Deve ter autonomia para executar suas funções e ser cobrada quanto ao desempenho e alcance dos objetivos.

Entretanto, a entidade coordenadora ou o próprio governo muitas vezes se envolvem com as questões estratégicas. Como aponta o documento, em alguns países há forte ligação entre os executivos das estatais e a entidade coordenadora ou diretamente com o governo, resultado do processo de indicação, que pode implicar o não envolvimento do conselho nas decisões, fazendo com que este se sinta menos responsável por prestar informações.

Também o papel do conselho de apontar e destituir o presidente da empresa é percebido como fundamental pela OCDE, de forma a permitir que o órgão possa exercitar plenamente sua função de monitoramento e se sentir responsável pelo desempenho da empresa.

Conforme informações da Secretaria do Tesouro Nacional (STN), ao final de 2007, a União detinha participação majoritária em 50 empresas (27 sociedades de economia mista e 23 empresas públicas) e minoritária em 81 empresas, não consideradas as participações acionárias de órgãos e entidades da administração federal indireta (Secretaria do Tesouro Nacional, 2008). Considerando que o Decreto no 757, de 19 de fevereiro de 1993, estabelece o teto de seis membros para o conselho de administração e de três membros efetivos e três suplentes para as empresas estatais, justifica destacar a importância do processo de nomeação, formação e acompanhamento da atuação desses conselheiros (Brasil, 1993).

As diretrizes dessa área são certamente de implementação complexa, embora de grande importância. Inibir a capacidade do conselho de exercer 
suas funções torna difusa a responsabilidade pelo desempenho da empresa, com impactos inclusive sobre os mecanismos de controle. É necessário um amadurecimento do processo político para que seja resguardada a empresa, enquanto ativo, e asseguradas condições para que seja capaz de atuar com essa independência.

\section{Considerações finais}

O ambiente da governança corporativa das empresas privadas no Brasil, mesmo considerados os desenvolvimentos ocorridos posteriormente às análises de La Porta, Lopez-de-Silanes e Shleifer (1998), aponta para a necessidade de uma evolução nas dimensões referentes ao arcabouço institucional-legal, nos modelos de prestação de contas da gestão, e no tratamento aos acionistas minoritários, para que as empresas se tornem mais competitivas na atração de recursos de investidores para financiar suas atividades. Por extensão, essa recomendação se aplica também às empresas estatais que, além dessas deficiências, têm a natureza difusa do controlador e a característica política de seu ambiente, tornando ainda mais crítica a exigência de consolidação das boas práticas de governança corporativa para ampliar a capacidade da ação dos gestores e a correta avaliação de seu desempenho. Nesse caso, a justificativa não é a atração de investidores - salvo nas sociedades de economia mista - mas o aumento da eficiência e eficácia na produção de bens e serviços públicos.

As diretrizes propostas pela OCDE para as estatais têm como tônica fortalecer a autonomia da empresa e dos conselhos. Ambos os aspectos podem trazer profundos impactos sobre o monitoramento e controle das empresas, dando visibilidade a custos usualmente não discriminados, relativos à execução de políticas públicas, permitindo separar a eficiência empresarial da estatal da ação governamental, cujo custo deveria ser mais claramente disposto no orçamento público. Só assim será possível promover a qualidade da gestão, a meritocracia e o direcionamento das responsabilidades pelo alcance dos objetivos.

É importante destacar também essas diretrizes que, ao estabelecerem arranjos que permitem ampliar a visibilidade da empresa estatal como ativo do governo, contribuem para promover o aumento da accountability e a maior estabilidade do trabalho de seus administradores, uma vez que os mecanismos de avaliação dos gestores tornam-se mais objetivos. À semelhança dos modelos de contrato de gestão, a adoção das diretrizes facilita a identificação dos resultados das empresas e o nível de realização de seus gestores, promovendo 
um círculo virtuoso pela busca de bons desempenhos e reduzindo interferências na sua atuação operacional. Ao propor a separação dos custos advindos da implementação de políticas governamentais daqueles gerados por eventuais problemas de ineficiência da gestão, as práticas propostas nas diretrizes poderão contribuir para melhorar a qualidade dos executivos das empresas estatais, já que a evidência de suas ações e resultados permitirá desenvolver as métricas de um sistema externo de controle para comparação de sua atuação com correspondentes privados.

Por ora, mesmo entre os países-membros da OCDE há vários aspectos dispostos nas diretrizes que exigirão significativas mudanças, principalmente quanto à centralização da função propriedade, critérios para seleção de conselheiros, e explicitação dos custos inerentes à função pública das empresas. Somem-se aos esforços de mudança as exigências particulares de cada país, visto que as profundas diferenças entre os modelos empresariais anglo-saxão, nipo-germânico, da Europa Meridional e da América Latina, presentes no sistema legal, nas práticas culturais e no nível de desenvolvimento dos mercados financeiros e ambiente institucional não são considerados de forma explícita no documento, por se pretender uma referência geral. Será necessário um esforço adicional - e uma reflexão mais ampla — para adequar aspectos das diretrizes ao ambiente brasileiro.

O principal mérito das diretrizes é apontar referências internacionais e possibilidades de solução para as questões próprias da governança das empresas estatais, respeitando sua natureza pública e sua importância nas economias nacionais. À medida que sua aceitação se amplie e suas diretrizes sejam internalizadas pelas empresas, aumentará a força dos movimentos que vinculam as boas práticas de governança ao desenvolvimento dos países, a exemplo do que já vem ocorrendo com as diretrizes de governança corporativa propostas para empresas privadas. As soluções encontradas pelos países para segui-las irão mostrar certamente exemplos de criatividade, inovação em gestão pública e organização do interesse político.

\section{Referências bibliográficas}

AMIHUD, Yakov; LEV, Baruch. Risk redution as a managerial motive for conglomerate mergers. The Bell Journal of Economics, Santa Monica, v. 12, n. 2, Autumn 1981.

BERLE, A.; MEANS, G. The modern corporation and private property. New York: MacMillan, 1932. 
BRASIL. Decreto-Lei no 200, de 25 de fevereiro de 1967. Dispõe sobre a organização da Administração Federal, estabelece diretrizes para a Reforma Administrativa e dá outras providências. Diário Oficial da República Federativa do Brasil, Brasília, DF, 27 fev. 1967. Disponível em: <www.senado.gov.br>. Acesso em: 5 mar. 2006.

. Decreto no 757, de 19 de fevereiro de 1993. Dispõe sobre a composição das Diretorias e dos Conselhos de Administração, Fiscal e Curador das entidades estatais que menciona. Diário Oficial da República Federativa do Brasil, Brasília, DF, 20 fev. 1993. Disponível em: <www.planejamento.gov.br/controle_estatais/conteudo/ legislacao/decreto/decreto_757_19_02_93.HTM>. Acesso em: 5 mar. 2006.

CARVALHAL, André. Estrutura de controle e valor das empresas brasileiras. In: LEAL, R. P. C.; FERREIRA, V. A.; SILVA, A. L. C. (Orgs.). Governança corporativa no Brasil e no mundo. Rio de Janeiro: E-papers, 2002, p. 45-58.

CARVALHO, Antonio Gledson de. Governança corporativa no Brasil em perspectiva. Revista de Administração, São Paulo, v. 37, n. 3, p. 19-32, jul./set. 2002.

COMISSÃO DE VALORES MOBILIÁRIOS. Panorama do mercado secundário internacional de valores mobiliários. Rio de Janeiro, 2003. Disponível em: <www.cvm. gov.br/port/public/ase/comparativo/Link_Comparativo.xls>. Acesso em: 12 mar. 2006.

DEPARTAMENTO DE COORDENAÇÃO E CONTROLE DAS EMPRESAS ESTATAIS. Empresas estatais federais por setor de atividade. Brasília, 1 fev. 2006. Disponível em: $<$ www.planejamento.gov.br/controle_estatais/conteudo/perfil/setor_atividade. htm >. Acesso em: 6 mar. 2006.

ESFAHANI, Hadi Salehi; ARDAKANI, Ali Toossi. What determines the extent of public ownership? Working paper, University of Illinois at Urbana-Champaign, 2002. Disponível em: < https://netfiles.uiuc.edu/esfahani/www/IndexFiles/Extent \%20of\%20Public\%200wnership.pdf>. Acesso em: 14 jul. 2005.

FITCH, Thomas. Dictionary of banking terms. Hauppauge: Barron's Educational Series, 1997.

LA PORTA, R.; LOPEZ-DE-SILANES, F; SHLEIFER, A. Law and finance. Journal of Political Economy, Chicago, v. 106, n. 6, p. 1113-1155, Dec. 1998.

LEAL, Ricardo Pereira Câmara; SILVA, André Luiz Carvalhal. Controle compartilhado e o valor das empresas brasileiras. RAC-eletrônica, Curitiba, v. 2, n. 2, art. 8, p. 296-310, maio/ago. 2008. Disponível em: <www.anpad.org.br/rac-e>. Acesso em: 18 ago. 2008.

McCRAW, Thomas K. (Org.) Alfred Chandler: ensaios para uma teoria histórica da grande empresa. Rio de Janeiro: FGV, 1998. 
ORGANIZATION FOR ECONOMIC CO-OPERATION AND DEVELOPMENT. Principles of corporate governance, 2004a. Disponível em: <www.oecd.org/dataoecd /32/18/31557724.pdf>. Acesso em: 17 jul. 2005.

. Draft comparative report on corporate governance of state-owned assets, Daffe/CA/Priv. Paris, 2004b. ms.

. Guidelines on corporate governance of state-owned enterprises, 2005. Disponível em: <www.oecd.org/document/33/0,2340,en_2649_37439_34046561_ 1_1_1_37439,00.html>. Acesso em: 17 jul. 2005.

OLIVEIRA, Eliane. Esforço fiscal depende de estatais federais. O Globo, 26 set. 2005. Disponível em: <http://oglobo.globo.com/jornal/economia/169944060. asp >. Acesso em: 27 set. 2005.

OMAN, Charles ; BLUME, Daniel. Corporate governance: a development challenge. Policy Insights, n. 3, OECD, 2005. Disponível em: <www.oecd.org/dataoecd/45/28/34342425.pdf>. Acesso em: 16 jul. 2005.

PEROTTI, Enrico. State ownership: a residual role? World Bank Policy Research Working Paper, n. 3.407, 2004. Disponível em: < http://wdsbeta.worldbank. org/external/default/WDSContentServer/IW3P/IB/2004/10/14/000012009_ 20041014130810/Rendered/PDF/WPS3407.pdf> . Acesso em: 17 maio 2005.

RIBEIRO, Alex; BORGES, André. PT e PMDB disputam cargos em bancos estatais. Valor Econômico, Brasil, p. A7, 11 abr. 2007.

RYAN, Christine; NG, Chew. Public sector corporate governance disclosures: an examination of annual reporting practices in Queensland. Australian Journal of Public Administration, Oxford, v. 59, n. 2, p. 11-23, jun. 2000.

SANZ, Luis; HOLÁN, Pablo Marín de. Reconquistando a confiança de acionistas minoritários. Harvard Business Review - Edição América Latina, Santiago, v. 82, n. 11, p. 36-41, nov. 2004.

SHLEIFER, A., VISHNY, R. A survey of corporate governance, The Journal of Finance, Oxford, v. 52, n. 2, p. 737-783, jun. 1997.

SECRETARIA DO TESOURO NACIONAL. Haveres mobiliários - participação da União. Brasília, Disponível em: <www.tesouro.fazenda.gov.br/haveres_uniao/ downloads/Participacao_Acionaria.pdf>. Acesso em: 22 jul. 2008.

THE COMMITTEE ON THE FINANCIAL ASPECTS OF CORPORATE GOVERNANCE. Report of the Committee on the financial aspects of corporate governance. London: Gee and Co. Ltd., Dec. 1992. Disponível em: <www.ecgi.org/codes/documents/ cadbury.pdf $>$. Acesso em: 3 mar. 2006. 